\title{
Escape from fear under alcohol: Fear inhibits alcohol-enhanced responding
}

\author{
CHRISTOPHER L. CUNNINGHAM and JUDSON S. BROWN \\ Oregon Health Sciences University, Portland, Oregon
}

\begin{abstract}
Ethanol's influence on the fear-arousing properties of a Pavlovian conditioned stimulus was assessed in an escape-from-fear paradigm. During the first phase, half of the rats were given tone-shock pairings (paired groups), and half received an equal number of tones and shocks in an unpaired manner (unpaired-control groups). Fear of the tone was assessed later by permitting rats to learn a locomotor response to escape a chamber in which the tone was presented. Type of fear conditioning was combined factorially with presence or absence of alcohol both during fear conditioning and during escape testing. Although initially slower than controls, paired groups increased their running speeds over test trials and eventually surpassed the control groups. Drug state during conditioning had no effect upon test performance, but the presence of alcohol during testing increased running speeds in both the paired and unpaired groups. Moreover, fear elicited by the tone in paired groups inhibited the arousing effect of alcohol on early test trials. These data do not support the hypothesis that alcohol reduces conditioned fear.
\end{abstract}

On the classical tension-reduction hypothesis, excessive alcohol consumption is viewed as learned instrumental behavior that has been powerfully reinforced by drug-mediated mitigations of tension or anxiety (Conger, 1956). Experiments designed to evaluate this hypothesis have commonly been carried out with animal subjects (Cappell \& Herman, 1972) and have entailed the assumption that human anxieties or tensions are paralleled, albeit roughly, by classically conditioned fears in animals. Thus, stimuli that have been paired with noxious events are assumed to elicit anticipatory fears, which, if the theory is correct, should be weakened by ethanol.

The effects of alcohol on fear have often been evaluated by means of an active avoidance paradigm, with some results favoring the tension-reduction view (e.g., Anisman, 1972; Berger, 1969) and others not (e.g., Baum, 1970; McMurray \& Jaques, 1959; Wallgren \& Savolainen, 1962). Unfortunately, in an active avoidance task, the conditioning of fear due to the pairings of apparatus cues and/or explicit conditioned stimuli (CSs) with unconditioned stimuli (USs) takes place during the learning of escape and avoidance responses, with shock-escape and avoidance trials being intermingled unsystematically. Any outcome, therefore, is difficult to interpret, since the drug may not only modulate

This research was supported by a training grant to J. D. Matarazzo (AA07074) and by a research grant to J. S. Brown (AA01229) from the National Institute on Alcohol Abuse and Alcoholism. Cynthia R. Cunningham and Johanna Nordlie are thanked for their assistance in running this experiment. $\mathrm{Re}$ print requests should be sent to the authors at the Department of Medical Psychology, Oregon Health Sciences University, Portland, Oregon 97201. the growth or expression of fear, but may also affect instrumental learning, or change the subject's sensitivity to shock, or alter fear's resistance to extinction. Moreover, the paradigm prevents the ready use of unpaired presentations of CSs and USs to control for nonassociative effects of exposure to these events.

Many of these problems can be eliminated through the use of the "acquired drive" or "escape from fear" paradigm (EFF) originally described by Miller (1948) and more recently by McAllister and McAllister (1971). In this paradigm, the fear-arousing capability of a Pavlovian CS is assessed by the degree to which its presence motivates and its removal reinforces an instrumental escape response. Since the conditioning of fear is separate from the learning of the escape response, independent estimates of the effect of the drug on the two phases become possible. Moreover, unpaired CS-US presentations can be administered to control subjects during the conditioning phase, and no subject is exposed to fear-conditioning contingencies during testing. The design also permits assessment of alcohol's stimulus properties and allows control for nonspecific drug effects. Finally, since shock is never presented during the testing phase, analgesia as a potential interpretation of drug-associated test-session differences is eliminated (Brick, Sun, Davis, \& Pohorecky, 1976).

During the first phase of the present experiment, half the rats were given tone-shock pairings to establish fear of the tone (paired groups). The remaining animals received the same number of tones and shocks in an unpaired manner (unpaired-control groups). The latter provided a reference level for evaluating the effects of alcohol on the condition- 
ing of fear. In the second phase, which involved a different apparatus, the animals were permitted to learn an instrumental locomotor response to escape nonshocked presentations of the tone. Type of fear conditioning (paired vs. unpaired presentations of CS and US) was combined factorially with presence or absence of alcohol (ip injections of the drug or saline) both during fear conditioning and during fear-escape testing $(2 \times 2 \times 2$ design). In addition, all groups were equated for exposure to alcohol and saline injections prior to escape training by administering a second injection of the opposite type several hours after conditioning.

Theoretical and empirical considerations suggest that during an EFF phase following aversive classical conditioning, subjects fearful of the CS will exhibit significant increments in escape speeds over trials, due to the reinforcement provided by responsecontingent fear reduction, whereas nonfearful controls will not. But since strong fear often leads to the suppression of activity (Blanchard \& Blanchard, 1969; Fanselow, 1980), fearful subjects may respond less quickly than nonfearful ones on early trials. After a time, however, the response reinforced by escape from the CS should become strong enough to override the incompatible freezing tendency and the asymptotic escape speeds of the fearful animals should surpass those of the controls (Brown \& Jacobs, 1949). If alcohol, when present either during the Pavlovian phase or during EFF trials weakens fear, as predicted by the tension-reduction notion, the initial inferiority of the fearful animals and/or their ultimate superiority should be diminished. Any general tendency for the drug to depress nonspecific locomotor or exploratory activity or to augment activity (e.g., Crabbe, Johnson, Gray, Kosobud, \& Young, 1982; Frye \& Breese, 1981) would be expected to affect performance in both fearful and nonfearful animals in the same way.

\section{METHOD}

\section{Subjects}

The subjects were 64 naive female Sprague-Dawley albino rats, 90-100 days old. They were individually caged and had free access to food and water. Their average weight during conditioning and testing was $227 \mathrm{~g}$.

\section{Apparatus}

Paired and unpaired presentations of the CS and US were administered in four small chambers $(22.5 \times 23 \times 15 \mathrm{~cm})$, each of which was enclosed in a ventilated, sound-attenuated box. The end panels were made of $1.5-\mathrm{mm}$ aluminum, and the side walls and ceiling were made of $6-\mathrm{mm}$ clear Plexiglas. The grid floor consisted of $2.3-\mathrm{mm}$ stainless steel rods mounted $1.27 \mathrm{~cm}$ apart.

The CS was the $4500-\mathrm{Hz}$ output of a Sonalert device (Mallory $\mathrm{SC} 628 \mathrm{H})$. The sound-pressure level of the tone was about $90 \mathrm{~dB}$ (re $20 \mu \mathrm{N} / \mathrm{m}^{2}$ ) measured at a point near the center of each chamber (Scott sound-level meter, Type 450-B, A scale). This was about $20 \mathrm{~dB}$ above the noise level produced by the ventilating fan in the conditioning chamber. The US was the $200-\mathrm{V}$ ac output of a step-up transformer wired in series with a resistance of $150 \mathrm{k} \Omega$ and delivered to each chamber via BRS (SC901) grid scramblers.

A two-compartment box was used during escape-from-fear testing. The compartments were each $10 \mathrm{~cm}$ wide $\times 30 \mathrm{~cm}$ long $\times 20 \mathrm{~cm}$ deep, and were separated by a manually operated guillotine door. One compartment was used as a startbox, and a Sonalert was attached to the end panel, $13 \mathrm{~cm}$ above the grid. A microswitch was actuated whenever the guillotine door was raised, and entrance into the goalbox was detected by a set of three photocells mounted on a vertical line $9 \mathrm{~cm}$ from the door. The other compartment served as a goalbox. The entire apparatus was painted a medium gray and was covered by a Plexiglas lid. A translucent white plastic tray extended the length of the box below the grid floor $(2.3-\mathrm{mm}$ stainless steel rods at $1.25-\mathrm{cm}$ intervals), diffusing light from 6-W light bulbs attached to the base. The apparatus rested on a table in a room illuminated only by the apparatus lights and a shielded 60 -W bulb directed toward the ceiling. A laboratory computer controlled stimulus presentations and recorded response latencies to the nearest $.02 \mathrm{sec}$.

\section{Procedure}

Apparatus exploration (Day 1). On the first day of the experiment, each rat was handled briefly and placed into one of the two compartments of the test box. The guillotine door was open and no stimuli were presented. After $5 \mathrm{~min}$, the animal was removed and was replaced into the compartment opposite that of the original placement for an additional $5 \mathrm{~min}$. Half the subjects in each group were placed into the startbox first and half into the goalbox first.

Conditioning (Day 2). On the next day, the rats were randomly assigned to eight equal-sized groups $(n=8)$. Animals in four of the groups were given ip injections of normal saline (salineconditioned groups); the remaining groups received ethanol in a saline solution (alcohol-conditioned groups). The experimenter administering the injections was "blind" as to the contents of the syringes. Two to $3 \mathrm{~min}$ after injection and placement into the conditioning chamber, the first of 25 presentations of a 6-sec tone CS and a 2 -sec shock US was given. For two of the groups in each drug condition (paired groups), CS onset preceded US onset by $4 \mathrm{sec}$ and trials occurred at intervals averaging $90 \mathrm{sec}$ $( \pm 30)$. Rats in the other groups (unpaired controls) also received a tone and a shock in each trial interval, but the order of presentation was random and the interval separating stimulus onsets averaged $45 \mathrm{sec}( \pm 15)$.

Because of the size of the experimental design, only one dose of alcohol was used. An intermediate dose level, $.8 \mathrm{~g} / \mathrm{kg}$ (in a volume of $7.5 \mathrm{cc} / \mathrm{kg}$ ), was selected on the basis of evidence of its behavioral effects on other paradigms and because it was not expected to produce ataxia (see Wallgren \& Barry, 1970). Although the time interval between injection and the first conditioning trial was short, previous research had suggested that bloodethanol levels reached their peak in less than 10 min after ip injection and that overall levels remained relatively high during a time period comparable in length to that of the conditioning session (about $40 \mathrm{~min}$ ) (see Linakis \& Cunningham, 1979).

In order to equalize animals for exposure to alcohol and saline before testing, each rat was given an injection in its home cage 2 to $3 \mathrm{~h}$ after the last conditioning trial. Animals that had received alcohol during conditioning were injected with saline, and animals given saline during conditioning were injected with alcohol.

Testing (Day 4). Forty-eight hours after the conditioning session, the animals were given 25 fear-escape trials in the oneway box. Two minutes before the first trial, a "blind" injection was given. One paired group and one unpaired group from each of the training-drug conditions received ethanol $(.8 \mathrm{~g} / \mathrm{kg})$ before testing (alcohol-tested groups); the remaining groups received saline (saline-tested groups). On each trial, the rat was placed 
in the startbox facing the door. As the lid closed, the door was raised, turning on the tone and activating a timer. The CS terminated and the timer stopped when the rat broke the photocell light beam in the goalbox or when $60 \mathrm{sec}$ had elapsed. If the rat failed to escape within $60 \mathrm{sec}$, it was gently pushed into the goalbox. After $15 \mathrm{sec}$ in the goalbox, the animal was returned to the startbox for another trial until 25 trials had been completed. For analysis, response latencies were converted to speed scores by reciprocal transformation. The alpha level for all statistical analyses was set at .05 .

\section{RESULTS}

As has been suggested above, performance in an escape-from-fear situation is believed to reflect the combined influence of tendencies to locomote out of the fear-arousing environment, of fear-produced motivation, and of fear-elicited tendencies to "freeze." Since, on early test trials, the learned tendency to escape should be quite weak, the response speeds of the fearful animals should not differ from those of the controls despite the higher level of fear motivation of the former. Indeed, on the assumption that "freezing" should be the dominant response, one might expect that the escape speeds of the fearful animals would be slower initially than those of the controls. With additional escape trials, the responses of the fearful animals should be strengthened by fear reduction and their escape speeds should eventually surpass those of the controls.

These expectations are supported by Figure 1 in which the escape speeds of the paired and unpairedcontrol groups (averaged across drug treatment) have been plotted against successive blocks of five trials. The visually apparent interaction of fearconditioning treatment with trials was supported

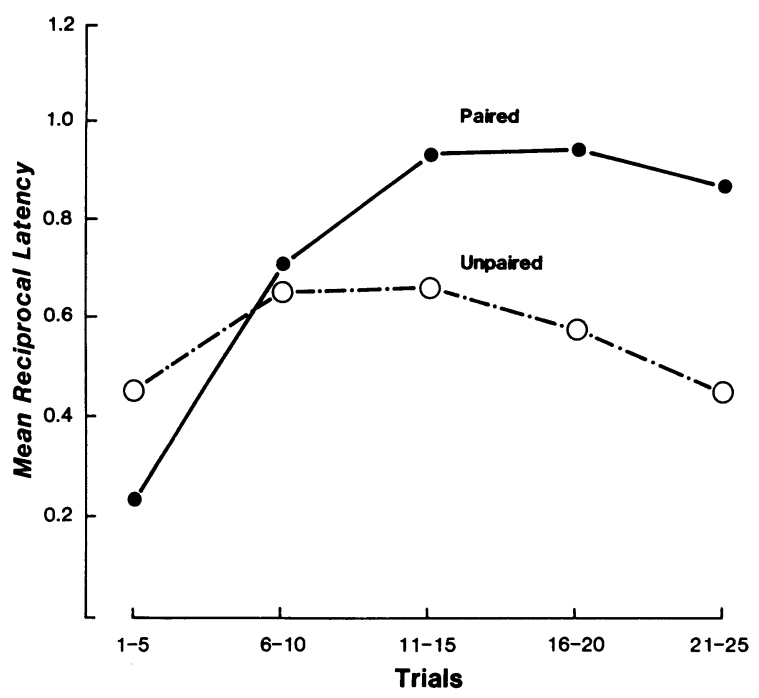

Figure 1. Mean reciprocal escape latencies in five-trial blocks during escape-from-fear testing for the paired and unpairedcontrol groups (collapsed over drug conditions).

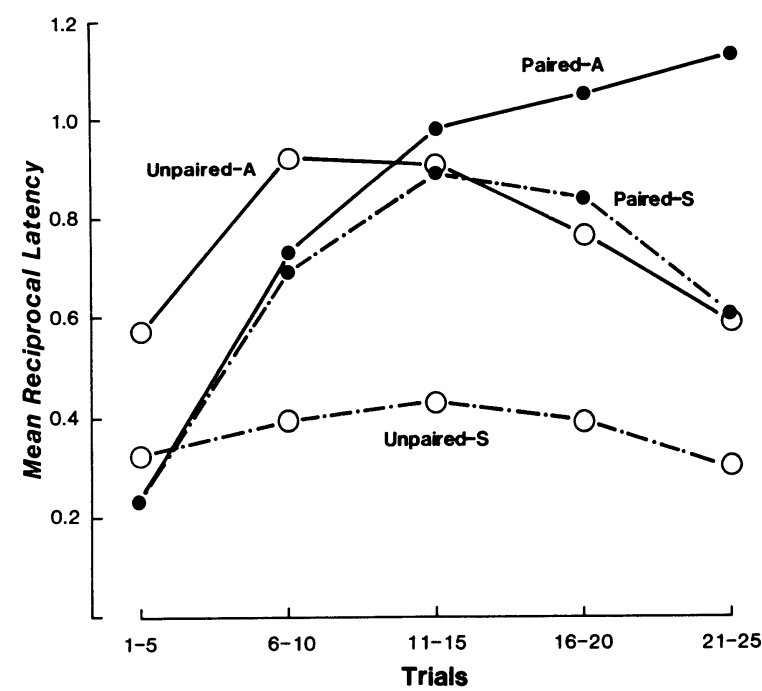

Figure 2. Mean reciprocal escape latencies in five-trial blocks during escape-from-fear testing as a function of conditioning group and test drug. Closed symbols represent paired groups, whereas open symbols represent unpaired-control groups. Solid lines show groups tested under alcohol; dashed lines show groups tested under saline.

statistically by the outcome of an overall analysis of variance involving the factors of fear conditioning, drug during fear conditioning, drug during escape testing, and trial blocks. Specifically, the interaction in Figure 1 was significant $[F(4,224)=8.9]$, with follow-up comparisons indicating significant group differences at both the first and last blocks of trials $[\mathrm{Fs}(1,56)=24.0$ and 5.6, respectively].

The overall analysis also revealed that the presence of alcohol during fear conditioning was not an influential factor during escape-from-fear testing, either as a main effect or as part of any higher order interaction (all Fs $<1$ ). However, when the drug was introduced during testing, it definitely augmented escape speeds $[F(1,56)=5.4]$, although its effects were not the same for paired and unpaired groups in each trial block.

The mean escape speeds of paired and unpaired subgroups tested with and without the drug are shown in Figure 2. These curves reveal that the interaction in Figure 1 was due far more to the difference between the two alcohol-tested subgroups (paired-A and unpaired-A) than to that between the saline-tested subgroups (paired-S and unpairedS). This conclusion was supported in the overall analysis by a three-way interaction of fear conditioning $\times$ test drug $\times$ trial blocks $[F(4,224)=2.6]$. The saline subgroups exhibited an interaction between fear conditioning and trial blocks $[F(4,112)$ $=4.2$ ], differing on the second and third blocks $[F s(1,56)>4.3]$, but not on the first $[F(1,56)=2.0]$. In comparison, the two alcohol subgroups (paired$A$ and unpaired-A) exhibited a marked performance 
difference on the first trial block $[F(1,56)=30.3]$, a significant conditioning $\times$ trial blocks interaction $[F(4,112)=6.7]$, and a significant last-block difference $[F(1,56)=4.6]$ that was opposite in direction to that on the first block. Figure 2 thus makes it evident that the overall interaction seen in Figure 1 was due largely to an alcohol-induced increment in response speeds that was contravened on early trials by the suppressive effect of fear and amplified on later trials by the reinforcing effect of escapecontingent fear reduction.

\section{DISCUSSION}

In this experiment, animals that received forward pairings of a CS (tone) and US (shock) during Pavlovian fear conditioning showed significant improvements over trials in speed of escape from the CS in a new situation. Control animals given unpaired presentations of the CS and US failed to learn the escape-from-fear task. The performances of the saline-tested groups (paired-S and unpaired-S) shown in Figure 2 illustrate these outcomes, which are consistent with Mowrer's (1947) two-factor theory and with the findings of other investigators (Brown \& Jacobs, 1949; McAllister \& McAllister, 1971; Miller, 1948).

The question of whether alcohol mitigates fear, as predicted by the tension-reduction conception, involves two different subissues. One is whether the drug affects the acquisition of fear during Pavlovian aversive conditioning. The other is whether fear is modified by alcohol after it has been acquired. The design used in this study was intended to provide answers to both of these questions. As to the first, the fact that the fear-conditioning phase, with and without alcohol, was carried out prior to, and independently of, the subsequent EFF tests made it possible to estimate the effects of alcohol on the conditioning of fear. Analyses of our data revealed that the presence of the drug during conditioning had no effect on subsequent escape speeds. Moreover, the absence of any interaction between training drug and test drug suggests that statedependent learning did not occur. Apparently, a moderate dose of alcohol does not affect the conditioning of fear.

This result differs from that reported by Anisman (1972) in the only other study designed to separate the effects of alcohol on the conditioning of fear from its effects on the performance of a fear-motivated locomotor response. He reported that injection of a somewhat higher dose of ethanol $(1.2 \mathrm{~g} / \mathrm{kg})$ before fear conditioning eliminated the anticipated improvement in subsequent shuttle-avoidance performance, and he interpreted the finding as being consistent with a fear-reduction conception. This discrepancy between our outcome and Anisman's may be due to any of several procedural or parametric differences. One potentially critical difference is that Anisman did not deliver unpaired shocks to his fear-conditioning control groups. Thus, his effect of drug during conditioning cannot unambiguously be attributed to alcohol's impact on the conditioning of fear.

The absence of shock during the fear-escape phase of the present design simplifies interpretations of the susceptibility of test performance to the influence of alcohol. Of special interest in this study was the finding that alcohol tended to elevate response speeds more or less uniformly throughout the testing phase in nonfearful animals (cf. unpaired-A vs. unpaired-S in Figure 2). This augmentation effect is perhaps best construed as a nonspecific arousal such as that reported by other investigators (e.g., Frye \& Breese, 1981). The performances of the paired-A and paired-S groups provide an interesting contrast. As Figure 2 shows, both paired groups were extremely slow on the first trial block, but the paired-A group was responding more quickly than all other groups by the last block of trials. This group was like the unpaired-A group in being tested under alcohol but differed in that it was fearful, whereas unpaired-A was not. It seems reasonable to suppose, therefore, that fear initially suppressed activity, thereby contravening the tendency for alcohol to enhance locomotor responding. Under these conditions, it must be concluded that alcohol did not attenuate fear. Instead, fear attenuated the responseenhancing effect of alcohol. With additional trials, the fear-escape response was strengthened by fear reduction, despite the fact that fear itself was probably becoming weaker through nonreinforcement. The significant terminal superiority of the paired-A group over the paired-S group $[F(1,56)=4.4]$ may thus be construed as reflecting the combined effects of response-contingent reinforcement and a weakening of fear that permitted the dynamogenic action of alcohol to become evident.

The occurrence of a dynamogenic effect of alcohol on motor behavior is consistent with the outcomes of several shock escape/avoidance studies (Amit, Ziskind, \& Baum, 1973; Anisman, 1972; Baum, 1969, 1970, 1971; Brick et al., 1976; Broadhurst \& Wallgren, 1964; Chesher, 1974; Di Giusto \& Bond, 1977; Holloway, 1972; Mansfield, Eaton, Cunningham, \& Brown, 1977; Reynolds \& Van Sommers, 1960; Skurdal, Eckardt, \& Brown, 1975; Wallgren \& Savolainen, 1962). An important contribution of the present study is that its design permits us to conclude that, in this case, alcohol's ability to improve performance is clearly due to nonassociative processes.

The finding that strong fear inhibits alcohol's 
activating effect may also help to explain some of the apparent inconsistencies that have arisen in studies of alcohol's effects during avoidance acquisition and extinction. For example, the fact that alcohol sometimes elevates intertrial responding while not affecting avoidance responding (e.g., Anisman, 1972; Broadhurst \& Wallgren, 1964) could be due to the fact that strong fear elicited by the avoidance signal suppresses alcohol-induced arousal more than does weak fear evoked by apparatus cues. The same mechanism may also explain why alcohol's dynamogenic influence on responding tends to appear early in avoidance training (Anisman \& Waller, 1974; Holloway, 1972) or during extinction (e.g., Baum, $1969,1970,1971)$, but not late in avoidance acquisition. Simply stated, alcohol's arousing effects are apparent only when fear evoked by explicit CSs or environmental stimuli is relatively low.

Unfortunately, the present experiment does not address one additional question raised by these data in light of earlier findings. Specifically, it is not known whether the general dynamogenic effect of alcohol observed in the unpaired groups depended somehow on their prior exposure to electric shock. This issue is raised by the finding of Frye and Breese (1981) that alcohol increases shuttlebox responding (both during and between signal presentations) only if shock is also presented. Thus, it may be that alcohol's ability to augment locomotor behavior depends on both low levels of fear and a history of exposure to shock.

The foregoing analysis offers little support for alcohol's reputed tension-reducing ability in studies of fear-motivated locomotor behavior. In fact, it would appear that many of the findings in this area can be better explained without reference to tension reduction by appealing to the following facts: (1) alcohol impairs motor behavior (i.e., produces ataxia) at high doses; (2) at low to moderate doses, alcohol may enhance motor performance, perhaps to a greater degree or only after exposure to shock; (3) strong fear can inhibit alcohol-induced arousal; (4) alcohol can reduce sensitivity to shock (analgesiclike effect) in a dose-dependent manner; and (5) in some circumstances, alcohol can have responseeliciting cue functions.

\section{REFERENCES}

Amit, Z., Ziskind, D., \& Baum, M. Drug effects and avoidance extinction in rats: A test of the drug novelty hypothesis using ethanol. Animal Learning \& Behavior, 1973, 1, 41-43.

Anisman, H. Fear reduction and active avoidance learning after alcohol administration during prior CS-shock exposure. Quarterly Journal of Studies on Alcohol, 1972, 33, 783-793.

Anisman, H., \& Waller, T. G. Effects of alcohol on discriminative active avoidance in mice. Quarterly Journal of Studies on Alcohol, 1974, 35, 439-444.
Baum, M. Paradoxical effect of alcohol on the resistance to extinction of an avoidance response in rats. Journal of Comparative and Physiological Psychology, 1969, 69, 238-240.

BAUM, M. Effect of alcohol on the acquisition and resistanceto-extinction of avoidance responses in rats. Psychological Reports, 1970, 26, 759-765.

BAUM, M. Effect of alcohol on the resistance-to-extinction of an avoidance response: Replication in mice. Physiology \& Behavior, 1971, 6, 307-309.

Berger, H. J. Chlorpromazine and ethanol combination: Effects on respiration, random motor activity and conditioned avoidance-escape in mice. Quarterly Journal of Studies on Alcohol, 1969, 30, 862-869.

Blanchard, R. J., \& Blanchard, D. C. Crouching as an index of fear. Journal of Comparative and Physiological Psychology, 1969, 67, 370-375.

Brick, J., Sun, J. Y., Davis, L., \& Pohorecky, L. A. Ethanol and the response to electric shock in rats. Life Sciences, 1976, 18, 1293-1298.

Broadhurst, P. L., \& Wallgren, H. Ethanol and the acquisition of a conditioned avoidance response in selected strains of rats. Quarterly Journal of Studies on Alcohol, 1964, 25, 476-489.

Brown, J. S., \& JAcobs, A. The role of fear in the motivation and acquisition of responses. Journal of Experimental Psychology, 1949, 39, 747-759.

Cappell, H., \& Herman, C. P. Alcohol and tension reduction: A review. Quarterly Journal of Studies on Alcohol, 1972, 33, 33-64.

Chesher, G. B. Facilitation of avoidance acquisition in the rat by ethanol and its abolition by a-methyl p-tyrosine. Psychopharmacologia (Berlin), 1974, 39, 87-95.

Conger, J. J. Reinforcement theory and the dynamics of alcoholism. Quarterly Journal of Studies on Alcohol, 1956, 17, 296-305.

Crabbe, J. C., Johnson, N. A., Gray, D. K., Kosobud, A., \& Young, E. R. Biphasic effects of ethanol on open-field activity: Sensitivity and tolerance in C57BL/6N and DBA/2N mice. Journal of Comparative and Physiological Psychology, 1982, 96, 440-451.

DiGiusto, E. L., \& Bond, N. Enhancement of pseudoconditioning and retardation of escape by low doses of ethanol. Pharmacology, Biochemistry \& Behavior, 1977, 6, 175-177.

FAnselow, M. S. Conditional and unconditional components of post-shock freezing. Pavlovian Journal of Biological Science, 1980, 15, 177-182.

Frye, G. D., \& Breese, G. R. An evaluation of the locomotor stimulating action of ethanol in rats and mice. Psychopharmacology, 1981, 75, 372-379.

Holloway, F. A. State-dependent effect of ethanol on active and passive avoidance learning. Psychopharmacologia (Berlin), 1972, 25, 238-261.

Linakis, J. G., \& Cunningham, C. L. Effects of concentration of ethanol injected intraperitoneally on taste aversion, body temperature, and activity. Psychopharmacology, 1979, 64, 61-65.

Mansfield, J. G., Eaton, N. K., Cunningham, C. L., \& Brown, J. S. Ethanol and avoidance-avoidance conflict in the rat. Physiological Psychology, 1977, 5, 197-203.

McAllister, W. R., \& McAllister, D. E. Behavioral measurement of conditioned fear. In F. R. Brush (Ed.), Aversive conditioning and learning. New York: Academic Press, 1971.

McMurray, G. A., \& Jaques, L. B. The effects of drugs on a conditioned avoidance response. Canadian Journal of Psychology, 1959, 13, 186-192.

Miller, N. E. Studies of fear as an acquirable drive: I. Fear as motivation and fear-reduction as reinforcement in the learning of new responses. Journal of Experimental Psychology, $1948,38,89-101$. 
Mowrer, O. H. On the dual nature of learning: A reinterpretation of "conditioning" and "problem solving." Harvard Educational Review, 1947, 17, 102-148.

Reynolds, G. S., \& Van Sommers, P. Effects of ethyl alcohol on avoidance behavior. Science, 1960, 132, 42-43.

Skurdal, A. J., Eckardt, M. J., \& Brown, J. S. The effects of alcohol on escape learning and on regular and punished extinction in a self-punitive situation with rats. Physiological Psychology, 1975, 3, 29-34.
Wallgren, H., \& Berry, H., III. Actions of alcohol. Amsterdam: Elsevier, 1970.

Wallgren, H., \& Savolainen, S. The effect of ethyl alcohol on a conditioned avoidance response in rats. Acta Pharmacologica et Toxicologica, 1962, 19, 59-67.

(Manuscript received December 9, 1982;

revision accepted for publication March 2, 1983.) 